\title{
DEBATE SOBRE O TOTALITARISMO: A TROCA DE CORRESPONDÊNCIAS ENTRE HANNAH ARENDT E ERIC VOEGELIN
}

\author{
Daiane Eccel \\ é doutora em Filosofia e professora de Filosofia da Educação na Universidade Federal de \\ Santa Catarina (Ufsc).Florianópolis, SC.Brasil.E-mail:<daianeeccel@hotmail.com>.
}

http://dx.doi.org/10.1590/0102-141174/101

As questões relacionadas ao totalitarismo talvez sejam o aspecto da obra de Arendt que mais tenha chamado a atenção dos especialistas ao longo de todos esses anos. A razão para tamanho interesse provavelmente encontra-se na própria natureza dos acontecimentos decorrentes da Segunda Guerra Mundial, ou seja, as máquinas de morte no sombrio período do século XX. No prefácio da primeira edição de Origens do totalitarismo, escrito no verão de 1950, Arendt anuncia o estado de espírito de sua época:

Duas guerras mundiais em uma geração, separadas por uma série ininterrupta de guerras locais e revoluções, seguidas de nenhum tratado de paz para os vencidos e de nenhuma trégua para os vencedores, levaram à antevisão de uma terceira guerra mundial entre as duas potências, que ainda restavam. O momento de expectativa é como a calma que sobrevém quando não há mais esperança. (2004, p. 11)

Hannah Arendt foi apenas uma entre outros intelectuais que, apesar de tomar conhecimento do horror das 
câmaras de gás somente na década de 1940, percebeu a potencialidade assassina dos regimes políticos de seu tempo já na década anterior. Com Eric Voegelin, não na Alemanha, mas na Áustria pós Anschluss, a situação não foi diferente. O estudioso do curso de Direito, até então assistente do jurista e filósofo Hans Kelsen em Viena, percebeu os perigos que estavam por vir (embora ninguém fosse capaz de imaginar o quão longe eles iriam chegar) e opôs-se ao regime totalitarista alemão. Como afirma Dietmar Herz (2005, p. 10):" "a Gestapo havia preparado 'listas negras' com os nomes dos oponentes ao regime. Eles eram demitidos dos cargos públicos - se eles tivessem sorte. Caso eles tivessem menos sorte, eram abordados e levados aos campos de concentração ou assassinados. O nome de Voegelin estava em uma dessas listas". ${ }^{2}$ Em função disso, segundo Monika Puhl (2005, p. 21), com ajuda de amigos, fugiu para os Estados Unidos em 1938, seis anos depois de casar-se com Lissy, cujos pais eram simpatizantes do nacional-socialismo e tinham um quadro de Hitler na parede da sala de estar. Enquanto a história de Voegelin é semelhante à de outros autores que, apesar de não judeus, opuseram-se ao regime por meio da filosofia ou da arte, a história de Arendt - relembrada por quase todos os seus comentadores quando o assunto ronda as questões relacionadas ao totalitarismo - foi exatamente igual à de muitos outros judeus da época: perseguição, perda de direitos políticos, fuga da Alemanha para a França, estadia em um campo de trabalho, fuga do campo de trabalho e, finalmente, a fuga para a América do Norte. No "novo mundo" americano, a vida

\footnotetext{
1 Herz é responsável pelo prefácio da obra de Monika Puhl, Eric Voegelin in Baton Rouge.

2 "The Gestapo hat prepared 'blacklists' with the name of the opponents to the regime. They were dismissed from public officers - if they are less lucky, they were arrested, taked to concentration camps or murdered. The name Erich Voegelin was one of the lists."
} 
dos dois também se assemelhou à de muitos outros intelectuais imigrantes europeus: a busca por uma casa, dificuldades iniciais com o idioma, tentativa de entender os hábitos e maneira de pensar dos norte-americanos, sobrevivência com o auxílio de fundações, esforço pela busca de notícias de parentes e amigos na Europa, procura de um emprego e espera pela cidadania estadunidense para que então pudessem novamente pertencer a algum lugar no mundo. Mais do que essas questões práticas, porém, permanecia para todos a pergunta que os fazia pensar constantemente: em que a República de Weimar havia se transformado? O que aconteceu com a Alemanha do período entre guerras?

A pergunta que não queria calar passou a atormentar Hannah Arendt depois que a perseguição acirrada aos judeus havia começado no final da década de 1920, mas, antes disso, seus estudos eram dedicados às questões quase puramente teológico-filosóficas, como aquelas que rondavam sua tese de doutorado sobre o conceito de amor em Santo Agostinho. Arendt e Voegelin começaram a atentar para os estudos sobre os regimes totalitários quase concomitantemente, no início da década de 1930. Voegelin, porém, foi mais ousado e, em certo sentido, mais promissor do que Arendt, pois, em 1933, seu escrito Raça e Estado já estava sendo publicado. Dele, seguiu-se no mesmo ano A ideia de raça na história do espírito, o Estado Autoritário, de 1936, e finalmente o livro que despertaria a ira dos membros do Partido Nacional Socialista: As religiões politicas, em 1938. A ousadia de Voegelin lhe custou caro e o preço pago foi a fuga para os Estados Unidos da América. Na década de 1930, o problema que ocupava os pensamentos de Arendt estava diretamente relacionado ao problema que ela enfrentava como judia e que mais tarde compôs a primeira parte das Origens do totalitarismo. Em 1933, ela escrevia sobre a vida da judia Rahel Varnhagen e seu movimentado salão literário em Berlim, no século XIX. Ao mesmo tempo, Arendt refletia igualmente sobre a situação dos judeus contemporâneos de 
Varnhagen que, sem direitos políticos, contentavam-se com os benefícios cedidos pela nobreza e pelas posições privilegiadas que ocupavam nos bancos europeus. Nessa época, porém, Arendt ainda não havia se dedicado às questões referentes ao cerne do problema dos regimes totalitários e nem tentado diagnosticar uma causa para a ascensão do Führer ao poder. Embora ela percebesse o perigo potencial da situação dos judeus, bem como a potencialidade totalitária do governo de Hitler na década de 1930, somente mais tarde ela realmente parece ter-se dado conta da situação pela qual havia passado. Em uma entrevista concedida a Günter Gaus na TV alemã em $1964,{ }^{3}$ Arendt revela que:

tivemos que acreditar seis meses mais tarde, quando comprovamos o que tinha ocorrido. Isso é que foi perturbador. Anteriormente dizíamos: 'Bom, nós temos inimigos. É a ordem natural das coisas. Por que um povo não teria inimigos?'. Mas foi completamente diferente. Foi na verdade como se um abismo se abrisse diante de nós, porque tínhamos imaginado que todo o resto iria de alguma maneira se ajeitar, como sempre pode acontecer na política. Mas dessa vez não. Isso jamais poderia ter acontecido. E não estou me referindo ao número de vítimas, mas à fabricação sistemática de cadáveres. (Arendt, 2002, p. 135)

A catástrofe anunciada e a própria situação da fuga de Arendt fizeram que a autora voltasse seus olhos para o mundo da política e conduziram à reflexão não somente sobre a situação do totalitarismo em si, mas também sobre quais rumos a política estava tomando nesses tempos sombrios. O livro que consagrou Arendt como estudiosa da política Origens do totalitarismo - é resultado de todo o processo pelo qual ela mesma passou desde o final de 1920 até sua chegada

3 Texto presente na coletânea A Dignidade da Política. 
aos Estados Unidos. Comentadores afirmam que essa obra deu início a uma série de outras que servem ou como resposta a Origens do totalitarismo (como seria o caso de A condição humana, publicada sete anos depois), ou como continuidade (como o relato de Eichmann em Jerusalém, escrito em 1963), entremeada com mais uma série de escritos entre e depois desse período. Enquanto o ponto de partida de Arendt foi sua própria situação como judia e sua indignação diante da situação política da Alemanha nazista, o de Voegelin foi a associação entre sua capacidade de refletir sobre o que aconteceu à sua volta e seus estudos de Direito na Universidade de Viena, bem como sua desconfiança com os movimentos de massa que haviam ganhado força na década de 1920. Arendt e Voegelin têm, portanto, o mesmo objeto de estudo: a política e os movimentos totalitários do século XX. As teses de Arendt são amplamente conhecidas (e igualmente criticadas em alguns aspectos). As de Voegelin, por sua vez, carecem de leitura e de divulgação, mas ambas, com suas diferenças e particularidades, constituem o núcleo deste artigo.

No caso de Voegelin, a situação é ainda mais complexa, já que muitos de seus conceitos são completamente desconhecidos no meio acadêmico e certamente exigirão um esforço maior para esclarecê-los. A elucidação de tais conceitos constitui o cerne de sua teoria não somente sobre os regimes totalitários, mas também sobre sua proposta de uma nova ciência da política. Para além do esclarecimento das teses de ambos os autores sobre o totalitarismo em si, o objetivo deste artigo é mostrar em que medida o pequeno debate travado entre Voegelin e Arendt é importante para a compreensão do problema dos conceitos de verdade - que serão tratados adiante neste estudo - e da política, debate este tão desconhecido quanto os conceitos voegelianos e no qual as diferenças de diagnóstico dos dois autores são bem nítidas. Apesar de não ser constituído por mais de vinte páginas, esse debate traduz exatamente o que eles entendiam pelas causas do movimento 
totalitário e revela as tendências teóricas e influências de formação que carregaram consigo ao longo de suas vidas. $\mathrm{O}$ objeto de inquietação de ambos é sempre o mesmo: a ascensão do totalitarismo. As respostas para as perguntas que rondam o problema, no entanto, são distintas e serão analisadas aqui.

\section{0 debate}

Em função de toda essa organização e sistematicidade inerente ao domínio totalitário, o espanto de Arendt ficou evidente na conhecida entrevista a Günter Gaus para a TV alemã. A ausência de razões militares para o novo regime e a falta de pretensão econômica contrastadas com os horrores dos campos de concentração dotaram todos esses acontecimentos de uma aparência de irrealidade e loucura. Todo o espanto de Arendt com a notícia dos campos, aliado à sua própria história, fez surgir as Origens do totalitarismo, com observações inovadoras para o campo do pensamento político, mas também alvo 146 de muitas críticas, como fica explícito nas palavras de YoungBruehl (1997, p. 233): "quando Hannah Arendt escreveu essa carta eufórica a Blumenfeld, ${ }^{4}$ seu livro Origens do totalitarismo acabava de sair, com críticas entusiasmadas". Entre todas as críticas, duas recebem destaque e as demais podem ser consideradas "mais do mesmo" com relação a essas duas. Trata-se da resenha de Eric Voegelin publicada na Review of politics, bem como a do sociólogo David Riesman publicada na Commentary. ${ }^{5}$

\footnotetext{
4 Trata-se de uma carta em que Arendt descreve a Blumenfeld o sucesso de algumas palestras sobre filosofia das artes ministradas pelo seu marido, Blücher.

5 Além disso, Young-Bruehl também destaca que as críticas de tendências marxistas surgiram depois da publicação da segunda edição da obra, bem como a crítica de Raymond Aron. Arendt e Aron conheceram-se durante a estadia dela em Paris. Uma das principais críticas que Aron fez a Arendt está relacionada com a maneira como ela se apropria da teoria das formas de Montesquieu e, por meio disso, foca sua ampla análise nos problemas que envolvem as considerações de Arendt sobre o monopólio de um único partido, bem como o terror totalitário e as ideologias. Para além disso, Aron ainda reitera o fato de que Arendt negligenciou a categoria de religião secular, que poderia ser um elemento fundamental para a compreensão da ascensão dos regimes. É Peter Baehr quem se ocupa das críticas de Aron a Arendt. Para tanto, conferir Baehr (2010).
} 
Enquanto Eric Voegelin foca sua atenção em alguns problemas pontuais na obra de Arendt, Riesman tece algumas considerações sobre o método da autora e questiona suas conclusões advindas de certas falhas metodológicas. ${ }^{6}$

O ponto que importa aqui, porém, são as controvérsias estabelecidas no pequeno - mas nem por isso menos importante - debate entre Voegelin e Arendt, que é erroneamente ignorado e tem propositalmente sua importância mitigada por parte de alguns comentadores de ambos os autores. ${ }^{7}$

A resenha de Voegelin publicada na Review of Politics em 1952 a convite de Waldemar Gurian é resultado da troca

6 Importa notar que Arendt e Riesman travaram um diálogo no período em que o autor estava trabalhando em sua obra mais conhecida, The lonely crowd (A multidão solitária), de 1950. Nela, Riesman preocupa-se em analisar o caráter das classes médias urbanas modernas, bem como a alienação dos indivíduos. $\mathrm{O}$ autor herda de Max Weber a análise dos tipos ideais, bem como a forma de ação dos indivíduos que, segundo ele, seriam influenciados por uma orientação tradicional, introdireção e alterdireção, a depender do período correspondente da história social. Segundo Baehr (2010) que se esmera em detalhar o debate entre Arendt e Riesman, ambos tinham poucas coisas em comum: tratam de diferentes países e focam em problemas distintos, mas eram judeus secularizados, tinham opiniões semelhantes sobre a criação do Estado de Israel e concordam sobre os sentimentos de falta de indignação e de uma apatia generalizada por parte das massas. A principal diferença entre ambos resguardava-se no foco de atenção de cada um deles ao tratar da sociedade de massas e da ascensão dos regimes totalitários. Nesse sentido, Riesman critica a análise arendtiana que, ao tratar da ascensão dos regimes, mantém seu foco em elementos como a polícia secreta, propaganda do partido e demais aparatos relacionados ao partido e líderes, mas não leva devidamente a sério outros processos sociais e elementos descentralizados que também contribuíram. Embora o debate entre Arendt e Riesman não esteja publicado em língua portuguesa, é possível encontrar o livro de Riesman (1995). Para análise apurada do debate entre os dois pensadores, recomenda-se novamente o livro de Peter Baehr supracitado, já que este autor dedica um capítulo para as querelas instauradas entre Arendt e Riesman.

7 Em língua portuguesa, a única fonte dedicada ao debate, é um capítulo localizado no livro de Sylvie Courtine-Denamy, O cuidado com o mundo: diálogo entre Hannah Arendt e alguns de seus contemporâneos, traduzido do francês e publicado pela editora da UFMG. Em inglês, encontramos os textos de Peter Baehr e Barry Cooper que serão citados aqui e em alemão, encontramos uma coletânea dos textos de Arendt referentes ao totalitarismo que trazem seus textos e os de Voegelin e que, ao final, são apreciados por meio de um comentário de Ingeborg Nordmann. Com relação a este último, conferir LUDZ, Ursula (org). Über den Totalitarismus: Texte Hannah Arendts aus den Jahren 1951 und 1953. Dresden: Hannah ArendtInstitut für Totalitarismusforschung, 1998. 
epistolar entre Voegelin e Arendt. ${ }^{8}$ As cartas não são muitas e, com exceção do conteúdo referente à opinião de Voegelin sobre a obra de Arendt, as demais não contêm informações relevantes para nosso trabalho. Mas a troca de correspondência iniciada por Voegelin em 16 de março de 1951 dá origem à resenha encomendada por Waldemar Gurian. A resenha e sua réplica são versões mais "impessoais" das cartas trocadas, mas a força das ideias e a sequência da argumentação é a mesma, de forma que tais cartas - a resenha de Voegelin e a réplica de Arendt - podem ser facilmente identificadas com o mesmo conteúdo. O que Waldemar Gurian fez foi apenas publicar as cartas de ambos em uma versão adaptada para a revista. ${ }^{9}$

Em 1952, finalmente surge a resenha de Voegelin na Review of Politics. Voegelin a inicia afirmando que "a imensa maioria dos seres humanos que estão vivos sobre a Terra se veem afetados em alguma medida pelos movimentos

8 Arendt refere-se a Voegelin em outras ocasiões e critica sempre o mesmo ponto,
a saber, a tese das religiões políticas. Tanto no texto "Religião e Política" (1953)
quanto em "O interesse pela política no pensamento filosófico recente" (1954),
ambos presentes em A Dignidade da política, Arendt menciona Voegelin referindo-se
a esse aspecto. Além disso, ela também toma conhecimento do seu A nova ciência
da política logo quando a obra é publicada e escreve a Gertrud e Karl Jaspers, em
novembro de 1952, afirmando se tratar de um "livro importante", com questões
que devem ser pensadas e com uma leitura atenta sobre Max Weber. Courtine-
Denamy relata que Arendt o tem em conta e afirma sua importância, porque "pri-
meiramente seu autor [...] faz prova de preocupação pelo político, pela preserva-
ção do mundo" (2004, p. 146). Ainda sobre a recepção de A nova ciência da política
por Arendt, afirma que "definitivamente, e não obstante seu elogio ao livro, parece
que Arendt não o via senão como mais uma dessas 'rajadas do Zeitgeist', reapare-
cendo sempre a cada vinte anos" (2004, p. 151).
9 As correspondências estão acessíveis nos arquivos de Voegelin, em Stanford,
dos quais há também cópia na biblioteca pessoal de Voegelin em Erlangen, na
Alemanha. Sobre as demais correspondências entre os dois autores, há apenas
menções sobre uma cordial amizade entre eles e a respeito de telefonemas e peque-
nos possíveis encontros em ocasiões em que Voegelin estava em Nova Iorque ou
Arendt próxima de algum lugar onde Voegelin lecionava ou passava férias. Além
disso, Voegelin ainda convidou Arendt para uma conferência em seu Instituto de
Ciência Política em Munique, em 1961 , ou seja, exatos dez anos após a primeira
troca de correspondências e próximo ao julgamento de Eichmann, em Jerusalém. 
totalitários de massa do nosso tempo"10 (Voegelin, 2000, p. 15) ${ }^{11}$ e, a partir daí, passa a adotar um vocabulário que lhe é comum: as metáforas de um diagnóstico médico, como alguém que flagra patologias na modernidade "como se a putrefação da civilização ocidental houvesse liberado um veneno cadavérico que propaga a infecção por todo o corpo da humanidade" (2000, p. 15). ${ }^{12}$ Segue-se como consequência o fato de nem a filosofia política e tampouco a ciência política terem instrumental teórico adequado para pensar as questões do totalitarismo, pois tal fenômeno necessita ser entendido à luz de um conjunto de saberes que deveria "abarcar desde as experiências religiosas até as transformações da personalidade sob a pressão do medo e das atrocidades, passando pelas instituições de governo e organização do terrorismo" (2000, p. 15).$^{13}$ Mas trata-se, neste caso, de um ciclo vicioso, já que essa falta de instrumental teórico é justamente causada pelo próprio estado decadente no qual se encontra a civilização ocidental, ou seja, uma civilização incapaz de atentar para os fenômenos do espírito e que não consegue desenvolver uma antropologia filosófica para tal fim. O problema no estudo inadequado do totalitarismo é a perspectiva sob a qual ele é analisado, e aí está também, segundo Voegelin, o problema de Arendt, que tem seu trabalho prejudicado, entre outras coisas, pelo fato de deixar-se levar demais pelas emoções diante das atrocidades acometidas nos regimes totalitários, obnubilando o foco central

\footnotetext{
10 A fonte usada para citar a resenha de Voegelin é o texto em inglês publicado na coletânea de suas obras completas. Ao passo que, cada vez que citarmos a réplica de Arendt, faremos uso do texto contido na coletânea Compreender: formação, exílio e totalitarismo.

11 "The vast majority of all human beings alive on earth are affected in some measure by the totalitarian mass movements of our time".

12 "The putrefaction of Western civilization, as it were, has released a cadaveric poison spreading its infection through the body of humanity."

13 "by subject matter the inquiry will have to ranger from religious experiences and their symbolization, through governmental institutions and the organization of terrorism."
} 
do problema e abdicando de um referencial teórico adequado, já que o horror moral e a carga emocional eclipsam o essencial e "levam a uma delimitação da matéria do objeto de exame” (2000, p. 17). Embora o livro de Arendt esteja repleto de "formulações brilhantes e intelecções profundas" (Voegelin, 2000, p. 16), falha ao perseguir as consequências de tais intelecções, pois "sua elaboração sofre uma virada até uma superficialidade lamentável” (Voegelin, 2000, p. 16)..$^{14}$ Mas esse aspecto seria apenas a revelação de que Arendt também padece da confusão intelectual e moral que assola a modernidade. No entanto, Voegelin realiza uma breve reconstrução do argumento de Arendt sobre o declínio do Estado-nação, bem como de outros fatores econômicos que, segundo Arendt, influenciaram na ascensão do regime. Além disso, o autor faz questão de marcar quais os pontos altos do texto de Arendt e elogia sem restrição a primeira parte - sobre o antissemitismo -, afirmando que é "talvez 150 o melhor resumo histórico que há acerca do problema do antissemitismo", enquanto a segunda parte "é a mais penetrante do ponto de vista teórico" (2000, p. 18).$^{15} \mathrm{O}$ que Voegelin admira é a capacidade de Arendt associar vários fenômenos que normalmente são vistos de forma dispersa, como a expansão do imperialismo dos Estados nacionais e a formação de elites e populachos.

O texto de Voegelin está repleto das influências de seus estudos sobre religião, e também fica clara sua tendência a interpretar os fenômenos históricos baseados em suas leituras frequentes do historiador-economista britânico Toynbee. ${ }^{16}$

\footnotetext{
14 "It abounds with brilliant formulations and profound insights - as one would expect only from an author who has mastered her problems as a philosopher - but surprisingly, when the author pursues these insights into their consequences, the elaboration veers toward regrettable flatness."

15 "The second part - on Imperialism - is theoretically the most penetrating".

16 Para perceber a influência de Toynbee sobre Voegelin, basta lembrar da grandiosa e reconhecida obra escrita pelo britânico que contém 12 volumes e trata da história de 26 civilizações. O opus magnum de Voegelin, Ordem e história, constituída
} 
Ao tratar das questões do método e das fontes utilizadas no estudo de Arendt, Voegelin afirma que há muitas formas de tentar enxergar o fenômeno totalitário e diz não saber se, efetivamente, a maneira adotada por Arendt é a melhor, apesar do fato de merecer um tratamento cuidadoso. Nesse contexto, Voegelin se pergunta por qual motivo Arendt não fez uso dos conceitos e do estudo de Toynbee, e afirma que, em questão de método, o livro não atinge o rigor esperado, e a descrição dos fenômenos históricos aliados à situação social "tendem a envolver a causalidade histórica com aura de fatalidade" (2000, p. 20). ${ }^{17}$ Isso configura um problema para Voegelin, porque não são apenas os fatos históricos os mais decisivos para essa interpretação do problema, mas a forma como as pessoas lidam com isso. Aparece aqui a problemática da liberdade espiritual e das virtudes - que é bastante comum nos escritos voegelianos - e que o conduz à conclusão de todo seu estudo sobre o totalitarismo: "a enfermidade espiritual do gnosticismo é o problema específico das massas modernas e os paraísos e os infernos fabricados pelo homem são seus sintomas" (Voegelin, 2000, p. 20). ${ }^{18}$ A tarefa de esclarecer o totalitarismo, portanto, não se resume em apenas explicar o surgimento das sociedades de massa e abarcar outros dados históricos, mas consiste em investigar o motivo pelo qual os homens desse tempo deixaram que a história tomasse esse rumo. Para Voegelin, Arendt falha em sua análise, pois segundo Young-Bruehl (1997, p. 235): "Voegelin havia argumentado que o retrato que Arendt fazia da falência política e social era convincente, mas que ela deixara de considerar os vários tipos de resposta a essa falência" e, com isso, erra o foco

de cinco volumes, tem uma sequência parecida com aquela estabelecida por Toynbee. Os doze volumes de Toynbee se encontram na biblioteca pessoal de Voegelin, em Erlangen, na Alemanha.

17 "to endow historical causality with an aura of fatality."

18 "The spiritual disease of agnosticism is the peculiar problem of the modern masses, and the man-made paradises and man-made hells are its symptoms". 
do problema, que está assentado na ascensão do gnosticismo na modernidade. Para manter-nos em apenas um exemplo, Voegelin sugere que, além de investigar razões sociais históricas que contribuíram para o totalitarismo já no século XVIII - como dissolução da nobreza e a ascensão da burguesia Arendt poderia também ter investigado o sectarismo imanentista da Baixa Idade Média e, portanto, especular sobre a situação espiritual dos homens para, posteriormente, talvez concluir que os movimentos totalitários "são movimentos de um credo imanentista no qual estavam frutificadas as heresias medievais" (Voegelin, 2000, p. 21). Tanto Voegelin quanto Waldemar Gurian ${ }^{19}$ tendiam a enxergar o totalitarismo como resultado do secularismo moderno e davam aos assuntos espirituais - os quais Arendt pouco ou nada considerava - um peso demasiado grande. Segundo Courtine-Denamy,

Desde as Religiões políticas, Voegelin sustentava a tese de que a grave crise que atravessava o mundo ocidental seria fruto da "secularização do espírito, da separação de um espírito que se tornou apenas mundano de suas raízes fincadas na religiosidade. Consequente, qualquer tentativa de se compreender uma dada situação política que desconheça as forças religiosas ativas na comunidade política, bem como os símbolos pelos quais se exprime, permaneceria necessariamente insuficiente. (2004, p. 142)

Ele abandonou a ideia de "religiões políticas" em voga em 1950 e, nos anos 1960, passou a concebê-la como "gnose" que aponta para um descarrilamento, patologia, desvio e fechamento da alma.

Mais do que esclarecer questões específicas da teoria de Voegelin e Arendt, importa entender quais os pontos-chave nos

\footnotetext{
19 Editor da Review of Politics e amigo comum de Arendt e Voegelin que sugeriu a resenha e deu a Arendt o direito de réplica.
} 
quais há discordância entre os dois autores. Segundo o italiano Roberto Esposito (2006, p. 101), há tamanho desencontro entre os autores a ponto de gerar um "mal entendido recíproco, ou pelo menos a incapacidade de perceber aquele quadro comum de problemas no interior do qual somente as diferenças, por certo relevantes e significativas, assumem significado e espessura". ${ }^{20}$ No texto de Voegelin aparecem duas críticas principais ao livro de Hannah Arendt. A primeira é justamente a falta de instrumental teórico adequado em função da ausência de uma antropologia filosófica ${ }^{21}$ bem elaborada que atentasse também para os fenômenos espirituais, e a segunda é uma espécie de explicação encontrada por Voegelin do porquê Arendt cometer essa falha. Voegelin acusa Arendt de adotar uma postura liberal, progressista e pragmatista diante dos problemas encontrados.

Mas o que provoca, afinal, Voegelin a criticar de forma tão contundente a autora de Origens do totalitarismo? Na terceira parte do livro, ao descrever as atrocidades cometidas nos campos de concentração, Arendt escreve:

O que as ideologias totalitárias visam, portanto, não é a transformação do mundo exterior ou a transformação revolucionária da sociedade, mas a transformação da própria natureza humana. Os campos de concentração constituem os laboratórios onde mudanças na natureza humana são testadas, e, portanto, a infâmia não atinge apenas os presos e aqueles que administram segundo critérios estritamente "científicos"; atinge todos os homens [...]. O que está em jogo é a natureza humana em si. (2004, p. 510, grifo nosso)

\footnotetext{
20 "da la impresión de un malentendido recíproco, o por lo menos de la incapacidad de percibir aquel cuadro común de problemas en el interior del cual solamente las diferencias, por cierto relevantes y significativas, asumen significado y espesor".

21 No caso de Voegelin, a ideia de uma antropologia filosófica remete à teoria da alma de Platão e Aristóteles e a uma concepção forte de natureza humana. Essa concepção de natureza humana se tornará clara quando chegarmos ao ponto crucial do debate entre Arendt e Voegelin.
} 
Para Voegelin, porém, a questão da natureza humana não pode ser tratada nesses termos de "mudança" e "transformação". Mostrou-se estupefato ao deparar com a passagem de Arendt sobre esse problema, pois, "quando li esta afirmação, apenas podia dar créditos aos meus olhos. 'Natureza' é um conceito filosófico e denota aquilo que identifica uma coisa como coisa desta classe e de nenhuma outra" (Voegelin, 2000, p. 21). ${ }^{22}$ Isso significa que a natureza humana não pode ser mutável, porque é essência, é fixa e pode ser conhecida e modificada por Deus, mas nunca pelo homem. No entanto, Arendt não pôde perceber isso porque estava ela mesma tomada pela desordem espiritual e intelectual do seu tempo e sucumbiu ao imanentismo, segundo o autor. Para Voegelin, Arendt era apenas mais uma vítima do obscurecimento dos conceitos de sua época e, por isso, está inclusa no grupo dos liberais, progressistas e pragmatistas, de forma que seus "descarrilamentos teóricos são, em 154 algumas ocasiões mais interessantes do que suas intelecções" (2000, p. 22)..$^{23}$

O problema da falta de aparato teórico associado à questão da natureza humana revela as pretensões metafísicas de Voegelin, que se tornam ainda mais claras no final de sua resenha, quando afirma que "a verdadeira linha de divisão na crise contemporânea não intercorre entre liberais e totalitários, mas entre transcendentalistas religiosos e filosóficos de um lado e liberais e imanentistas sectários totalitários por outro" (Voegelin, 2000, p. 22). ${ }^{24}$ Portanto, se Arendt crê na

\footnotetext{
22 "When I read this sentence, I could hardly believe my eyes. 'Nature' is a philosophical concept; it denotes that which identifies a thing as a thing of this kind and not of another one."

23 "We suggested previously that the author's theoretical derailments are sometimes more interesting than her insights"

24 "The true dividing line in the contemporary crisis does not run between liberals and totalitarians, but between the religious and philosophical transcendentalists on the one side and the liberal and totalitarian immanentist sectarians on the other side."
} 
possível mudança da natureza, está também no grupo dos liberais relativistas e imanentistas. Essa acusação do autor a Arendt, mediada pelos conceitos dicotômicos de imanentismo/transcendentalismo, revela mais do que nunca as tendências filosófico-metafísicas de Voegelin, já que tal acusação está assentada no argumento de que o totalitarismo é uma espécie de imanentização causada pelo secularismo. Nessa perspectiva, os movimentos totalitários do século XX têm origem na disputa espiritual entre imanentismo e transcendentalismo, de forma que a ascensão de tais regimes demonstra a vitória do primeiro sobre o segundo, na medida em que representam a tentativa de substituir o Deus transcendente por religiões seculares. Arendt, no entanto, segundo Voegelin, cai na cilada do próprio imanentismo ideológico e é condescendente com ele, seja quando não considera as questões espirituais para explicar as origens do totalitarismo, seja quando concorda que a natureza humana é mutável. Segundo Cooper (1999, p. 139), "a conclusão de Voegelin era clara: se a linha fundamental de divisão era entre religiosos e transcendentalistas filosóficos e uma rica variedade de imanentistas sectários, Arendt claramente se encontra entre os últimos". ${ }^{25} \mathrm{O}$ fato de Arendt deixar de considerar a evolução espiritual do Ocidente significa, para Cooper, a principal diferença metodológica entre os dois pensadores, e sobre o que motivou Arendt a não ter levado em conta este aspecto, diz Cooper (1999, p. 146): "é porque isso não lhe era visível no fenômeno totalitário". ${ }^{26} \mathrm{O}$ fato de ela desconsiderar um fenômeno que não é visível revelaria mais uma vez sua falta de sensibilidade para alguns ramos da filosofia que Voegelin leva em conta, como a filosofia da consciência, por exemplo.

\footnotetext{
25 "Voegelin's conclusion was therefore clear: if the fundamental dividing line was between religious and philosophical transcendentalist and rich variety of immanentist sectarians, Arendt clearly belonged among the later."

26 "because it was no visible to her in the totalitarian phenomenon."
} 
Voegelin fazia constante uso de termos medievais como auxiliares na tentativa de explicar fenômenos modernos. Em função disso, ele retoma a famosa disputa medieval entre nominalistas e realistas para tentar compreender o domínio totalitário. O nominalismo - apenas como flatus vocis - não concebe a existência dos universais e, segundo Voegelin, permite apenas um grau de investigação justamente porque não busca a essência da coisa. Nesse sentido, ele adota uma postura antinominalista forte e novamente fica claro seu platonismo, na medida em que leva em consideração a existência dos universais. Para Cooper (1999, p. 146), a dicotomia nominalismo versus realismo também seria uma forma de conceitualizar o debate entre Arendt e Voegelin, pois, enquanto este adota uma postura realista, Arendt tenderia mais para o nominalismo, ou mais especificamente, o que Voegelin chamava de taxonomia nominalista ou análise elementar. Na crítica de Voegelin, 156 ao insistir na importância de fazer distinções e traçar novamente uma tipologia das formas de governo baseada nas lições da tradição, mas acrescentando agora o totalitarismo, Arendt sucumbe à mera distinção conceitual superficial e permanece apenas no primeiro nível de investigação teórica. Tentar conceitualizar o domínio totalitário e marcar suas diferenças entre democracia liberal, monarquia constitucional e tirania clássica é uma tentativa que "aos olhos de Voegelin” permanece apenas elementar, pois fica só no nível do imanente. Qualquer investigação da tipologia das formas de governo permanece apenas no âmbito da taxonomia nominalista, pois só é possível alcançar uma investigação realística quando o objeto possui "status ontológico", e não quando é apenas um "acidente de ordem", como é o caso do totalitarismo como forma de governo.

Aqui se encontra a diferença essencial entre a forma como ambos enxergam o domínio totalitário: enquanto Arendt considera o totalitarismo uma nova forma que pode 
ser inclusa na tipologia dos regimes e, por isso, de cunho exclusivamente político (e, inquestionavelmente, a pior forma de regime que poderia haver), Voegelin o considera um fenômeno de desordem espiritual que, quando ignorado, torna obnubilado o diagnóstico. Se uma investigação realística só é permitida no plano do status ontológico, então devem ser consideradas "a natureza do homem ou da sociedade" ou "a ordem da alma humana”, pois só esses conceitos possuem esse status, o que não ocorre com formas de governo. Em função disso, a natureza do homem ou da sociedade ou a ordem da alma humana devem servir como pistas para a investigação acerca do totalitarismo, e campos como a antropologia filosófica têm o aparato necessário para tal investigação. O caminho que Voegelin privilegia é, portanto, o caráter mais transcendente e universal do fenômeno totalitário, enquanto Arendt se ocupa estritamente com questões histórico-políticas e, portanto, particulares. $\mathrm{O}$ "mal entendido recíproco" a que se refere Esposito passa, entre outras coisas, pela crítica de Arendt a Voegelin, pois ela teria reduzido a interpretação voegeliana sobre os regimes totalitários a dois pontos: a teleologia presente na filosofia da história de Voegelin e sua "teologia política". Esposito argumenta que Voegelin "desintegra a categoria do telos como âmbito de uma possível unificação do tempo histórico" (Esposito, 2006, p. 105) ${ }^{27}$ e que, se o autor tem uma filosofia da história (como realmente parece ter em Ordem e história), nada implica que ela seja teleológica. O encadeamento dos acontecimentos enumerados por Voegelin (teses sobre a gnose) desde a Antiguidade, passando pela Idade Média e chegando à modernidade, não significa que haja uma certa logicidade de fatos, mas, pelo contrário, segundo Esposito (2006, p. 104), que Voegelin “acentua e

\footnotetext{
27 "Hemos dicho que él desintegra la categoria de telos como âmbito de possible unificación del tiempo histórico.”
} 
radicaliza-os caracteres de descontinuidade e impredicabilidade de sua própria noção de tempo". ${ }^{28}$

A respeito da crítica de Arendt sobre uma ideia de teologia política, importa observar que essa expressão não é usada por ela. Ela se refere ao conceito "religião secular", sugerido por Voegelin. Arendt enfatiza que não seria capaz de utilizar tal termo porque não acredita que o lugar metafísico de Deus esteja já preenchido com alguma coisa.

\section{A réplica}

A defesa imediata de Arendt veio com o direito que lhe foi concedido por Gurian a uma réplica à resenha de Voegelin. No entanto, da mesma forma que ela já tinha conhecimento da opinião de Voegelin sobre Origens do totalitarismo por meio das cartas, ela também já havia lhe respondido através de correspondências e sua réplica publicada na revista é uma versão adaptada da troca epistolar. O interes158 sante é notar que, no caso de Arendt, há também referências a Voegelin na sua troca de cartas tanto com Jaspers quanto com seu marido, Blücher. Mas são tão poucas as referências quanto são as de Voegelin com relação à Arendt. Nelas, fica claro também um relacionamento de cordial amizade entre ambos, bem como respeito intelectual e discordância em alguns aspectos mais gerais da obra. Voegelin escreveu sua primeira correspondência a Arendt em 16 de março de 1951, e ela elaborou uma resposta datada de 8 de abril do mesmo ano. Porém, nunca a enviou. Ela reformulou tal texto em uma carta de 22 de abril. Segundo as observações de Baehr (2012, p. 366), "a primeira carta era não só mais longa como também mais informativa que a segunda" ${ }^{29} \mathrm{e}$ a pergunta que o comentador levanta é: por que Arendt

\footnotetext{
28 "Voegelin acentúa y radicaliza los caracteres de discontinuidad y de impredicabilidad de su propria interpretación del tiempo histórico."

29 "The first version, however, is not only longer but also more informative than the second."
} 
nunca teria enviado a primeira carta para Voegelin? Mas conforme ele também observa, a própria Arendt explicou isso quando, no envio da segunda carta, admite estar atrasada porque gostaria de dar uma resposta que abrangesse os vários pontos levantados por ele. No entanto, ela se deu conta de que, para isso, precisaria escrever algo que fosse mais do que uma carta e que, naquele momento, havia várias ideias ainda em fase embrionária. Alguns argumentos presentes na primeira carta são omitidos na segunda, talvez pelo fato de Arendt sentir-se na obrigação de desenvolvê-los com maior afinco antes de enviá-los a Voegelin e a simples omissão deles a desobrigaria deste ofício.

$\mathrm{Na}$ resposta de Arendt há três pontos que merecem especial atenção: a) o questionamento sobre a "falha" da tradição do pensamento político em "evitar" ou tentar responder às questões referentes ao totalitarismo; b) as consequências dessa falha como o não reconhecimento da importância da pluralidade humana; c) a forma como ela lida com as ideologias. A primeira e a última questão permanecem na segunda carta, enquanto a segunda, especificamente referente à pluralidade humana, é omitida na segunda carta.

Arendt acredita que uma das respostas para a questão do totalitarismo sugerida por Voegelin - a saber, a de que ele está diretamente relacionado com uma crise espiritual que em parte acontece em função do declínio do cristianismo no Ocidente - é abrangente demais para explicar um fenômeno tão específico como os regimes totalitários do século XX e que, ao invés de tentar encontrar uma explicação para isso, ela se esforça em fazer o exercício contrário, buscando responder por que a tradição do pensamento político filosófico, surgido desde Platão e arrastado até a década de 1920, não conseguiu responder às perguntas suscitadas pelo totalitarismo. Mas Arendt sabia que, nisso, Voegelin estava de acordo com ela, pois ele já havia anunciado que concordava com o fato de que não havia aparato intelectual inerente à tradição que fosse 
suficiente para explicar tal fenômeno. No caso de Arendt, porém, há um aspecto específico que precisa ser observado. No momento em que se pergunta o motivo pelo qual a tradição de pensamento político surgida com Platão não foi capaz de explicar os regimes totalitários, ela não faz simplesmente uma crítica à falta de aparato intelectual, mas critica, sobretudo, a separação entre a filosofia e a política que surgiu com a morte de Sócrates e que inaugura a força do pensamento político ocidental. Com a morte do mestre de Platão, a tradição política deixou de se importar com a pluralidade dos homens e, dentro do quadro de pensadores ocidentais, talvez Kant tenha sido o único a ser salvo deste mal. Por algum motivo, ela omite essa questão da pluralidade na carta para Voegelin, mas a retoma como argumento principal na resenha do ano seguinte, e esse é o aspecto que torna todo o pensamento político dela bastante original. Em Origens do totalitarismo, a questão da pluralidade já aparecia, principalmente na terceira parte referente 160 aos campos de concentração, mas ela realmente tomou força a partir da publicação de A condição humana (2010), momento no qual Arendt também sistematizou a relação entre a pluralidade humana e a falta de capacidade da filosofia política em lidar com este aspecto. Nas obras posteriores, Arendt sistematiza a ideia de que a filosofia falha com a política quando se ocupa apenas do homem, ao passo que a política se dá entre os homens. Na carta de 8 de abril de 1951, Arendt deixa clara sua percepção de que a onipotência do homem tornou os homens e sua pluralidade completamente supérflua e que, da mesma forma que a consequência lógica da onipotência de Deus é o monoteísmo, a consequência da onipotência do homem sobre os homens é o totalitarismo.

É ainda nesse contexto que Arendt retoma o problema suscitado por Voegelin sobre as ideologias. ${ }^{30}$ As considera-

30 Julgamos importante observar o uso tradicional do conceito de ideologia antes de adentrarmos em suas especificações na obra de Arendt e Voegelin. O Dicionário de Política alerta para o fato de que o uso do termo é "intrincado e múltiplo". 
ções um pouco mais vastas sobre ideologia na primeira carta são substituídas por uma enfática frase na segunda carta: "Eu acredito que odeio ideologias tanto quanto você" (Arendt apud Baehr, 2012, p. 379). ${ }^{31}$ Porém, a autora traça observações mais minuciosas sobre as ideologias que mais tarde servirão de conteúdo para o capítulo anexado em Origens do totalitarismo, intitulado "Ideologia e terror: uma nova forma de governo". ${ }^{32}$ A autora chama atenção para o fato de que nem sempre as ideologias exercem algum tipo de ameaça, principalmente quando elas meramente buscam oferecer um simples modo de vida para as pessoas. No entanto, em alguns contextos, elas podem se mostrar bastante perigosas, sobretudo quando o mundo no qual se está acostumado a viver sofre uma queda e tudo está desestruturado. A partir desse momento, caso predomine a "logicidade" das ideologias, o perigo começa a aparecer, e esse problema é amplamente debatido em "Ideologia e terror", em que Arendt afirma que a ideologia "é a lógica de uma ideia" (2004, p. 521). Há três características presentes nas ideologias que se manifestaram especificamente nos regimes totalitários: a) a pretensão de sempre tentar explicar o todo; b) o desejo de libertar-se de toda e qualquer experiência que de algum modo não contribua para os ideais perpetuados pela ideologia, mesmo que se trate de algo que acaba de acontecer; e c) a ideologia trata de enquadrar tudo dentro de uma fór-

Bobbio oferece uma "concepção fraca" e uma "concepção forte" de ideologia. Esta última trata da forma como Marx a concebe, ou seja, "é uma crença falsa". A concepção fraca designa apenas algo "que tem como função orientar os comportamentos políticos coletivos" (1995, p. 585).

31 "I believe I hate ideologies as much as you do."

32 Baehr observa que, conforme uma carta escrita a Marshall Macluhan, Voegelin acreditou que essa parte anexada posteriormente em Origens do totalitarismo fosse resultado de seus questionamentos para Arendt. Mas Baehr esclarece esse aspecto afirmando que alguns meses antes de receber a carta de Voegelin, Arendt já havia se debruçado sobre as reflexões a respeito deste tema, e prova disso foi sua conferência proferida na Universidade de Notre Dame, em 1950. A pretensão de Voegelin, portanto, era falsa. 
mula lógica para a qual parece não haver argumento capaz de rebater, já que tal processo é "absolutamente lógico" (2004, p. 523). Segundo Arendt, como na prática a ideologia é impotente, ou seja, ela mesma é incapaz de transformar a realidade existente, a construção lógica é a maneira encontrada para manipular a realidade. Arendt admite que, da mesma forma que na tipologia das formas de Estado de Montesquieu existem as molas propulsoras da ação, no totalitarismo - embora não se enquadre em nenhum tipo de forma de governo já conhecido - a ideologia é sua mola propulsora, ela é o princípio da ação junto com o terror. Essas informações são omitidas na segunda carta e, infelizmente, Voegelin teve acesso a elas somente posteriormente, o que o impediu de compreender a totalidade dos argumentos.

A resposta sobre o sentimentalismo excessivo com relação aos campos de concentração, bem como as questões de método e a questão relativa à natureza humana formam a 162 pauta principal da réplica de Arendt, agora não mais nas cartas. Antes disso, porém, ela faz observações mais gerais sobre o seu método e reconhece que "uma das dificuldades do livro é que ele não pertence a nenhuma escola, e não usa quase nenhuma ferramenta oficialmente reconhecida ou oficialmente controvertida" (Arendt, 2008, p. 418).

Embora reconheça que o moralismo ou o sentimentalismo seja sempre perigoso por parte do autor, ela afirma que reagir de forma totalmente indiferente aos horrores cometidos nos campos de concentração não seria rigor acadêmico, mas, mais do que isso, significaria perdoar o ocorrido. O propósito de Arendt com relação ao estudo do totalitarismo sempre ultrapassou as barreiras acadêmicas e tinha um papel também moral: compreendê-lo para evitá-lo. Ela reconhece que tratar da questão totalitária em termos históricos significa, de alguma forma, preservar tal questão, e isso, para a autora, não é exatamente um legado fácil, mas controvertido, dado o fato de "sentir-se empenhada 
em destruir" o totalitarismo (2008, p. 418). Arendt também afirma que, exceto essa contingência, a forma de sua escrita é apenas uma questão de estilo e que "houve quem o elogiasse por julgá-lo apaixonado, e quem o criticasse por considerá-lo sentimental" (2008, p. 419). Além disso, defende-se afirmando que há momentos na história nos quais faz parte da tarefa do historiador descrever as péssimas condições (sociais ou emocionais) de que padecem os agentes. Sem isso, a tarefa do historiador não fica completa, pois permanece descontextualizada. Assim, Arendt responde à acusação de Voegelin de que o excesso de sentimentalismo desvia o foco de atenção e encobre o que há de mais essencial no momento da análise.

Ainda quanto à diferença de método, Arendt insiste novamente no ato de fazer distinções e afirmar que não há precedente para os regimes totalitários. Isso significa dizer que a forma como Voegelin lê os regimes totalitários - a saber: como se fosse "apenas o outro lado do liberalismo, do positivismo e do pragmatismo" (2008, p. 421), jamais estaria correto porque não se trata simplesmente disso. A autora percebe que, no final das contas, ambos partem de pressupostos diferentes para interpretar o fenômeno e que, distintamente de Voegelin, que enxerga o totalitarismo de acordo com "influências e afinidades intelectuais" (2008, p. 421), ela interpreta de acordo com os fatos. Segundo Arendt, as influências platônicas de Voegelin são bastante evidentes e, em função disso, ele busca percorrer a essência do fenômeno, que estaria diretamente relacionado com o processo de decadência espiritual do mundo ocidental. $\mathrm{Na}$ medida em que tenta descrever alguns elementos históricos que de alguma forma contribuíram para a ascensão dos regimes totalitários, ela permanece, como Voegelin havia descrito, no nível dos fenômenos visíveis. Sobre isso, a própria Arendt concorda, assim como provavelmente concordaria que assume uma posição "nominalista", mas 
que isso não seria uma postura negativa. A posição diferenciada da qual partem Arendt e Voegelin marca todo o resto da réplica da autora que, recorrentemente, afirma que Voegelin interpreta os regimes totalitários a partir de ideias, e ela, a partir de fatos. A bem da verdade, Voegelin também o faz, mas os fatos para os quais ele se volta não estão todos dentro da modernidade, já que ele não enxerga ruptura entre o medievo e a modernidade mas, ao invés disso, uma continuação um pouco ao molde sugerido por Karl Löwith. Nesse sentido, vem à baila a questão da secularização e da novidade da modernidade também assinalada por Blumemberg ${ }^{33}$ que parece, em parte, estar agregada à teoria política arendtiana. Além das referências indiretas que faz a Voegelin em "Religião e política”, Arendt (2005) também retoma a questão no texto "O conceito de história: antigo e moderno”, em Entre o passado e o futuro. Ali Arendt parece

33 Na metade dos anos 1960, surge no cenário de pensamento germânico um debate acerca da legitimidade da modernidade sistematizado por Hans Blumemberg em obra homônima. Aparentemente e grosso modo, poderíamos afirmar de saída que Arendt partilha da tese de Blumemberg (sobretudo na reivindicação de que a modernidade não é uma mera continuidade dos tempos anteriores) enquanto Voegelin adere, em parte, à de Löwith. Voegelin é influenciado pelas teorias de Löwith e isso fica evidente, entre outros aspectos, pelas interpretações que ele tece sobre Joaquim de Fiori, autor para o qual Löwith destina um capítulo em seu conhecido Meaning in History, publicado em espanhol sob o título de Historia del mundo y salvación: os presupuestos teológicos de la filosofia de la Historia. Este é o grande livro de Löwith e foi publicado depois de De Hegel a Nietzsche. Nele, o autor se ocupa em investigar quais pressupostos religiosos se encontram por trás daquilo que chamamos de filosofia da história e questiona contundentemente as pretensões completamente novas e secularizadas que supostamente tomariam conta da modernidade ocidental altamente racionalizada. Não se trata de uma tentativa de retorno a uma maneira de interpretar as questões fundamentais sob o viés teológico, mas, antes de tudo, é um diagnóstico de tempo que desconfia do discurso a la Blumenberg que insiste em assegurar uma espécie de legitimidade da modernidade. A maior obra de Löwith (2007) se encontra acessível em espanhol. No entanto, essas considerações devem ser tratadas com maior cuidado, sobretudo em função das ressalvas presentes nas teorias desses autores. Neste escrito não trataremos dessa problemática e não nos ocuparemos de Karl Löwith e Hans Blumenberg. 
reforçar seu ceticismo com relação à ideia da modernidade como simples continuidade:

Secularização significa, antes de mais nada, simplesmente a separação entre a religião e a política, e isso afetou ambos os lados de maneira tão fundamental que é extremamente improvável que haja ocorrido a gradual transformação de categorias religiosas em conceitos seculares que os defensores da continuidade ininterrupta procuram estabelecer. (2005, p. 102)

$\mathrm{O}$ argumento de Arendt segue com coerência ao longo do texto, pois, justamente em função dessa posição um tanto fenomenológica, ela discorda completamente que o totalitarismo possa ser o resultado da falta de uma religião ou que, em outras palavras, o regime totalitário e seus líderes atuaram como uma religião secular em detrimento de um vácuo do cristianismo ou de qualquer outra religião. É por esse motivo que Arendt não adota o vocabulário voegeliano como "doença espiritual”, por exemplo, e, para além de não fazer uso de tais metáforas, Arendt discorda de que o que faz as massas serem massas é o fato de elas padecerem de uma doença espiritual que assola o Ocidente. Para ela, esse tipo de formulação permanece apenas no nível das ideias. Na leitura de Arendt, as massas se constituem como tal na medida em que são incapazes de perceber que partilham um mesmo mundo e que podem ter interesses em comum ao invés de atomizarem-se. Pensando dessa forma, Arendt deixa clara sua posição quanto ao papel da religião nos regimes totalitários, ou seja, não há nenhum papel significativo a ponto de tornar a religião ou a falta dela o foco central da explicação para tal fenômeno. A autora chega a reconhecer que há uma breve relação entre ateísmo e totalitarismo, no entanto, o efeito explicativo que tem o ateísmo assume apenas um 
papel negativo, e não positivo, ou seja, ele não é capaz de explicar o surgimento do totalitarismo e não pode ser explicado a partir do totalitarismo.

Afirmando que "o problema da relação entre essência e existência no pensamento ocidental me parece ser um pouco mais complicado e controvertido do que supõem as palavras de Voegelin sobre a "natureza'" Arendt (2008, p. 424) inicia sua defesa com relação àquela que considera a questão que atraiu as críticas mais ferrenhas de Voegelin. É sobretudo com relação a essa questão que Arendt mostra suas tendências intelectuais completamente diferentes e inclusive opostas a Voegelin. A autora não adentra diretamente o problema entre essência e existência, que se propõe a discutir no artigo "O que é filosofia da Existenz?", 34 mas ficam evidentes suas preferências por uma filosofia que trate mais da política como reino da pluralidade e menos 166 da metafísica. ${ }^{35}$ Ela afirma que, quando a liberdade deixa de fazer parte do homem, a natureza - imutável ou não não exerce grande papel. Por meio disso Arendt sinaliza também sua concepção de verdade, já que esta, em alguma medida, está relacionada com a metafísica. Refiro-me, neste momento, diretamente à verdade racional e não à verdade de fato. Esta última relaciona-se também com questões do totalitarismo e de sua propaganda totalitária, que é baseada mais na mentira organizada do que em verdades de fato. A verdade racional não precisa ter necessariamente suas raízes cravadas na metafísica, pode ser apenas teórica, mas, de qualquer forma, é caracterizada pela imutabilidade por

\footnotetext{
34 Texto presente na coletânea publicada em língua portuguesa como A dignidade da política (2002, pp. 15-38).

35 Entende-se aqui metafísica no sentido etimológico do termo, a saber, algo que está fora do nosso alcance e, por isso, que se desconhece de fato. Embora essa observação pareça desnecessária dada sua obviedade, é importante deixar claro que nesse contexto Arendt pretende pensar a política sem parâmetros metafísicos.
} 
excelência. Arendt não acredita que esse tipo de verdade esteja no reino da política e, quando está, representa perigo.

Diferente de Voegelin, que preocupa-se com a doença que assola a modernidade e adoece o espírito dos homens, refletindo as consequências dessa doença na política, Arendt está diretamente preocupada com os transtornos causados para a liberdade humana e busca, justamente na própria política e nos fatores históricos, explicações para isso. $\mathrm{O}$ que está em voga no caso de Arendt é a liberdade, mais do que qualquer discussão de cunho ontológico, como propõe Voegelin com a questão da natureza humana. Em seu ensaio sobre o sentido da política, Arendt (2006) afirma que política e liberdade estão intrinsecamente ligadas e que a liberdade é o sentido da política, assim como já o era na Grécia, contexto no qual ser livre e participar da vida política eram sinônimos. Em função disso, as tiranias e ditaduras são rebaixadas a patamares inferiores no regime das formas de governo, haja vista o fato de suprimirem a liberdade política dos homens. Mais radical do que qualquer tipo de tirania, despotismo ou ditadura, os regimes totalitários decepam definitivamente a possibilidade da liberdade não apenas no sentido político, mas também humano. Segundo Arendt: "o sucesso do totalitarismo equivale a uma liquidação muito mais radical da liberdade como realidade política e humana do que qualquer outra coisa que presenciamos antes dele" (2008, p. 424).

A posição de Arendt indica claramente sua divergência com o que ela chamava de filósofos profissionais, e no topo da lista estava Platão e o seu mundo das ideias. A discussão sobre a busca das essências pouco ou nada interessava a Arendt em sua investigação sobre o totalitarismo, já que essa pseudobusca desvia o investigador de sua questão e o faz cair no vício dos filósofos, a saber, aquele que desprende o pensador do mundo concreto e o conduz novamente ao mundo das ideias. Novamente, aqui é perceptível a crítica 
de Arendt aos filósofos e sua pretensiosa inclinação para a verdade (racional). A questão não é que Arendt negue tal verdade, mas assume que ela é pretensiosa demais quando busca lidar com a política, cujo reino é a opinião e a verdade de fato, não as verdades teóricas e suas imutáveis certezas. A verdade de fato, aquela que está diretamente relacionada com o mundo da ação, está também claramente suscetível à mentira. Em termos de ação, como afirma Arendt (2005) em "Verdade e política", age mais aquele que mente do que aquele que fala a verdade, do que aquele que só confirma os fatos. O chamado "dizedor da verdade" e testemunha dos fatos não tem a intenção de mudar ou mover o mundo; o mentiroso, o manipulador dos fatos, tem. Arendt, porém, traça diferenças entre a mentira tradicional - aquela que somente busca ocultar (mas que Kant, por exemplo, já combatia) e a mentira moderna, que deve ser considerada em parte quando o assunto é o totalitarismo. Para a mentira 168 moderna, o ocultamento não é suficiente, mas é preciso ainda modificar o contexto.

Aqui cabem algumas considerações sobre a mentira organizada em forma de propaganda nos regimes totalitários. Tanto Arendt quanto Voegelin atentaram para esse aspecto. Os líderes totalitários não precisavam de muito esforço, a não ser fazer uso dos problemas surgidos no período após a Primeira Guerra e elaborar propagandas e promessas. Arendt enfatiza que a propaganda foi o grande recurso estratégico por parte de ambos os regimes totalitários, já que as massas precisavam ser conquistadas de alguma forma. É interessante notar que se a estrutura e o domínio dos regimes totalitários eram inéditos e totalmente novos, o mesmo não acontece com as propagandas, que de forma alguma eram novas, mas apenas reaproveitavam velhos problemas com velhas promessas em uma roupagem cientificista, ou seja, trabalhavam com dados que supostamente a ciência era capaz de comprovar - como a superioridade da 
raça ariana no caso nazista, por exemplo. Nesse sentido, o caso que mais parece ter impressionado Arendt é a manipulação propagandística realizada pelos nazistas acerca dos famosos Protocolos de Sião. Baseados nesses documentos, que a princípio eram propagandas judaicas, os órgãos responsáveis pela propaganda nazista difundiram a ideia de que os Protocolos eram a tentativa de conspiração judaica para dominar o mundo e, dessa forma, "a propaganda nazista foi suficientemente engenhosa para transformar $\mathrm{o}$ antissemitismo em princípio de autodefinição, libertando-o assim da inconstância de uma mera opinião" (Arendt, 2004, p. 496). As propagandas eram os verdadeiros veículos doutrinários do poder totalitário, não somente para as massas, mas também para os próprios grupos ligados ao movimento, que sofriam influência direta por parte dos líderes. ${ }^{36}$ Não tardou, porém, para que a propaganda, que antes necessitava ter bases científicas - mesmo que se tratasse de puro embuste - fosse substituída pelo poder totalitário que, de forma alguma, precisava ser justificado.

Também em sua tentativa de compreender o ocorrido, Voegelin percebe a importância da propaganda e a disseminação da mentira, mas para tanto cita apenas o livro de Karl Kraus, A terceira noite de Valpúrgis, escrito em 1933, como exemplo de obra de alguém que, de alguma

\footnotetext{
36 Conferir, por exemplo, as considerações críticas que tanto Arendt quanto Voegelin fazem sobre as observações de Henry Picker em Hitlers Tischgespräche, ou seja, as conversas de Hitler com seus conselheiros militares e que, segundo Arendt, se tratavam de "discursos talhados para os ouvidos militares, com os quais esperava convencê-los de seus objetivos nacionais para prepará-los cautelosamente para seus verdadeiros projetos" (2008, p. 310). Voegelin, por sua vez, critica os escritos reunidos para a introdução de Hitlers Tischgespräche. Os ensaios são de Percy Ernst Schramm, um historiador reconhecido como de "alta conta" entre seus pares, como enfatiza Voegelin (2010, p. 78), que falha em tentar retratar Hitler em "A anatomia de um ditador" através de dados completamente irrelevantes e quase positivos como seus olhos "profundamente azuis, radiantes". Em Hitler e os alemães, Voegelin busca denunciar não somente as estratégias propagandísticas dos próprios nazistas, mas também a negligência alemã com os envolvidos no movimento no período pós-guerra.
} 
forma, tinha percebido as artimanhas propagandísticas nazistas. No entanto, diferente de Arendt, Voegelin não faz nenhuma análise detalhada explicando como a propaganda se disseminou. ${ }^{37}$

Nessa perspectiva, apesar de colocar o mentiroso dentro do espaço da ação, não significa, é claro, que Arendt seja uma defensora da mentira, mas, diferente disso, ela só retoma o caráter contingencial e imprevisível da ação.

Aqui são válidas algumas observações importantes sobre o texto no qual Arendt, remetendo a Leibniz, diferencia verdade de fato de verdade da razão. As verdades de fato são políticas por excelência na medida em que estão no mundo e são fatos que constituem o mundo onde vivemos. Ela é diferente da verdade racional cujo oposto é a opinião e, por este motivo, a doxa e a verdade de fato estão no mesmo domínio (Arendt, 2005, p. 294). A verdade racional, por sua vez, lida diretamente com a filosofia e, sobretudo, sempre 170 tendo Platão como interlocutor, Arendt concebe este tipo de verdade como associado à transcendência e à metafísica ou, em outras palavras, à solidão do filósofo: "a verdade de Platão, encontrada e realizada na solidão, por definição, transcende o âmbito da multidão e o mundo dos negócios humanos" (2005, p. 295). Ela contrapõe os dois tipos de verdade da mesma forma que contrapõe filosofia e política, a solidão do filósofo versus a pluralidade do mundo e a verdade contra a doxa, já que a formação desta última se dá no meio dos outros e só tem importância quando se está entre os homens.

Com isso, Arendt não se coloca certamente contra a filosofia, mas novamente desconfia do papel do filósofo quando este assume uma postura como a de Voegelin, por

\footnotetext{
37 Isso não significa afirmar que Voegelin não tenha tratado da propaganda nazista. Ele o fez em Hitler e os Alemães, sobretudo quando cita os episódios e as formas de propaganda relacionados à noite de Valpúrgis. No entanto, não sistematizou a análise, como fez Arendt.
} 
exemplo. E é preciso notar que é Platão quem está por trás dessa trama. Em uma carta a Karl Jaspers, em 1951 (portanto antes do debate com Voegelin), Arendt afirma que a filosofia naturalmente não é a culpada pelo que aconteceu com a Alemanha e com a Rússia na ascensão do mal radical, mas:

eu tenho a suspeita de que a filosofia não está inteiramente livre de culpa nisso tudo. Não, é claro, no sentido de que Hitler tivesse algo a ver com Platão [...] mas no sentido de que a filosofia ocidental nunca teve um conceito puro de política e não poderia ter tal conceito porque sempre falou do homem e tratou de forma marginal da pluralidade humana. (Arendt, 2013, pp. 126-7) ${ }^{38}$

Certamente isso não significa que Arendt desconsidere a importância da essência da natureza humana em termos filosóficos, ou que não reconheça o grande papel que este tema possui filosoficamente. Posteriormente, em A condição humana, ela se esquiva também desse tema quando diferencia a condição humana da natureza humana, deixando claro para o leitor que se manterá ocupada com o primeiro em vez do segundo termo. Arendt reconhece que a questão da natureza humana corresponde à pergunta: "o que sou?", que é diferente da questão "quem sou?". Esta última pode ser respondida com a simples constatação de que somos homens, ao passo que a primeira é, de fato, uma questão que conduz à reflexão sobre a essência do homem e sobre

\footnotetext{
38 Segue o texto no original: "Nun habe ich Verdacht, dass die Philosophie na dieser Bescherung nicht ganz unschuldig ist. Nicht natürlich in dem Sinne, dass Hitler etwas mit Plato zu tun hätte [...] Aber wohl in dem Sinne, dass diese abendländische Philosophie nie einen reinen Begriff des Politischen gehabt hat und auch nicht haben konnte, weil sie notgedrungen von dem Menschen sprach die Tatsache der Pluralität nebenbei behandelte.” Ainda com relação a esta citação, é importante observar que, na frase seguinte, Arendt admite que não deveria dizer isso, pois é muito imaturo e pede que Jaspers a desculpe.
} 
a qual - apesar de podermos conhecer a essência de muitas outras coisas - não podemos ter domínio. As considerações de Arendt inspiradas em Agostinho revelam que apenas um deus pode conhecer a natureza humana na medida em que foi ele quem criou o homem. No entanto, sob essa perspectiva, a questão deixa de ocupar os limites da filosofia e torna-se teológica, e só é resolvida "dentro da estrutura de uma resposta divinamente revelada" (Arendt, 2010, p. 12).

\section{Considerações finais}

O debate promovido por Arendt e Voegelin parece ser erroneamente ignorado e tem propositalmente sua importância mitigada por parte de alguns comentadores de ambos os autores. $\mathrm{O}$ erro na negligência de tal debate ${ }^{39}$ está relacionado não ao fato de ignorá-lo em si, mas com a falta de percepção de que ele é uma rica fonte de dados que revelam não somente as posições metodológico-investigativas de

172 ambos em relação aos regimes totalitários, mas, mais do que isso, os dois apresentam e defendem a compreensão que têm da política. Importa notar como os autores se mantêm coerentes com as posições teóricas que desenvolvem ao longo dos anos posteriores. O debate Arendt-Voegelin torna-se muito mais interessante do que os demais debates sobre o totalitarismo (excluindo, talvez, as querelas entre Arendt e os marxistas, que despertam outros problemas), porque há o fato de ambos terem partilhado a experiência de sair do seu próprio país e de terem visto o movimento nazista ganhar

\footnotetext{
39 Acerca desta negligência, gostaríamos de assinalar que ela provavelmente ocorre mais em função do desconhecimento da obra de Voegelin - o que não, certamente não acontecesse com a figura de Arendt. Porém, se em parte tal negligência se dá em função deste desconhecimento, por outro se dá por causa da constante associação com o nome do autor a uma espécie de conservadorismo platônico e fortes inclinações teológicas, - elemento que mitiga a curiosidade pela obra do autor e afasta o interesse de alguns comentadores, sobretudo em tempos nos quais as discussões da filosofia política se ocupam com outros debates como as disputas entre liberais e comunitaristas e com o surgimento de novos nomes da Teoria Crítica.
} 
força no final da década de 1920 e se estender ao longo da década seguinte. A experiência em comum gerou duas percepções distintas e explicações diferentes para o mesmo fenômeno e fez que as discussões fossem levadas para rumos distintos, pois enquanto Arendt - apesar de falhas metodológicas - buscou encontrar explicações para o fenômeno em alguns dados empíricos, assim como se preocupou em descrever a estrutura do movimento, Voegelin conduziu sua própria discussão para uma vertente que Arendt considerava de menor importância para a compreensão do tema: aquela sobre a relação entre política e religião. Embora esteja longe de ser o tema central de Arendt (ainda que em parte seja de Voegelin, ou ao menos do jovem Voegelin, já que trata da ideia de religiões políticas), essa discussão resultará em um ponto que é um dos cernes do pensamento de Arendt - a relação entre filosofia política e metafísica. Ademais, isso nos conduz também a um debate que parece bastante pertinente no cenário da filosofia política atual, a temática da secularização e a ideia bastante debatida acerca das teologias políticas.

\section{Daiane Eccel}

é doutora em Filosofia pela Universidade Federal de Santa Catarina (UFSC). Realizou estágio de doutorado sanduíche na Eric Voegelins-Bibliothek, na Friederich Alexander Universität em Erlangen/Nürnberg, Alemanha (2013-2014). Desde 2015, atua como professora de Filosofia da Educação na Universidade Federal de Santa Catarina. Ocupa-se com as teses de Hannah Arendt e Eric Voegelin e investiga as questões da formação humana (filosofia da educação) segundo o pensamento de Hannah Arendt.

\section{Bibliografia}

ARENDT, H. 2002. A dignidade da política. Rio de Janeiro: Relume Dumará. 2004. Origens do totalitarismo. São Paulo: Companhia das Letras. 2005. Entre o passado e o futuro. São Paulo: Perspectiva. 
2006. O que é política? 6. ed. Rio de Janeiro: Bertrand Brasil.

2008. Compreender: formação, exílio e totalitarismo. São Paulo:

Companhia das Letras; Belo Horizonte: UFMG.

2010. A condição humana. 11. ed. Tradução Adriano Correia. Rio

de Janeiro: Forense Universitária.

2013. Wahrheit gib es nur zu zweien: briefe an die freunde. München:

Piper.

ARENDT, H.; VOEGELIN, E. 2002. Debate sobre los orígenes del

totalitarismo. Claves de Razón Práctica, n. 124, pp. 4-11.

BAEHR, P. 2010. Hannah Arendt, Totalitarianism, and the Social Sciences.

Stanford: Stanford University Press.

. 2012. Debating totalitarianism: an exchange of letters between

Hannah Arendt and Eric Voegelin. History and Theory, v. 51, pp. 364-80.

BOBbiO, N.; MATTEUCI, N.; PASQUINO, G. 1995. Dicionário de Política.

Brasília: UnB. v. 1. pp. 585-97

COOPER, B. 1999. Eric Voegelin and the foundations of modern political science.

Columbia: University of Missouri Press.

COURTINE-DENAMY, S. 2004. O cuidado com o mundo: diálogo entre

Hannah Arendt e alguns de seus contemporâneos. Tradução Maria J. G.

Teixeira. Belo Horizonte: UFMG.

174 ESPOSITO, R. 2006. Categorías de lo impolítico. Buenos Aires: Katz.

HERZ, D. 2005. Vorwort. In: PUHL, M. Eric Voegelin in Baton Rouge.

München: Wilhelm Fink Verlag Periagoge. pp. 10-11.

LÖWITH, K. 2007. Historia del mundo y salvación: os presupuestos teológicos

de la filosofia de la Historia. Tradução Norberto Espinosa. Buenos Aires:

Katz.

PUHL, M. 2005. Eric Voegelin in Baton Rouge. München: Wilhelm Fink

Verlag Periagoge.

RIESMAN, D. 1995. A multidão solitária. Tradução Rosa Krausz e J.

Guinsburg. 2. ed. São Paulo: Perspectiva.

VOEGELIN, E. 2000. The collected works of Eric Voegelin: published essays 1953-

1965. Columbia: University of Missouri Press. v. 11. . 2010. Hitler e os alemães. São Paulo: É Realizações.

YOUNG-BRUEHL, E. 1997. Por amor ao mundo: a vida e a obra de Hannah

Arendt. Tradução Antônio Trânsito. Rio de Janeiro: Relume Dumará. 


\section{DEBATE SOBRE O TOTALITARISMO: A TROCA DE CORRESPONDÊNCIAS ENTRE HANNAH ARENDT E ERIC VOEGELIN}

DAIANE ECCEL

Resumo: Arendt e Voegelin debateram acerca do totalitarismo e, durante o ano de 1951, trocaram algumas correspondências. No ano posterior, as cartas foram transformadas em resenha e publicadas na Review of Politics. Arendt responde aos comentários de Voegelin e assim se constitui a pequena conversa entre ambos. Tal debate é pouco conhecido no Brasil e, apesar de ser pequeno, revela as tendências de pensamento de Arendt e Voegelin, pois nele estão contidas ideias que serão desenvolvidas posteriormente no pensamento de ambos, como é o caso do "gnosticismo" para Voegelin e da "pluralidade" para Arendt. No debate, ficam evidentes as diferentes tendências de pensamento para os autores, e tal diferença se manifesta, sobretudo, na querela levantada por Voegelin acerca da "imutabilidade da natureza humana".

Palavras-chave: Totalitarismo; Religiões Políticas; Pluralidade; Natureza Humana.

\section{DEBATE ABOUT THE TOTALITARIANISM: THE CORRESPONDENCE BETWEEN HANNAH ARENDT AND ERIC VOEGELIN}

Abstract: Hannah Arendt and Eric Voegelin discussed about the Totalitarianism and during 1951 changed correspondences. The following year, the letters were published in Review of Politics in review format. Arendt replies to the Voegelin's comments and so borns the talk between them. This debate is little-known in Brazil, but despite being small, the debate reveals how both think about the Totalitarianism and other categories of Arendt's and Voegelin's thought like the "gnosticism" for Voegelin and "plurality" for Arendt. In the debate the differences of thought are obvious. This difference 
Resumos | Abstracts

is manifest when Voegelin questions Arendt on the "immutability of human nature".

Keywords: Totalitarianism; Politics Religion; Plurality; Human Nature.

Recebido: 23/07/2015 Aprovado: 11/11/2016 